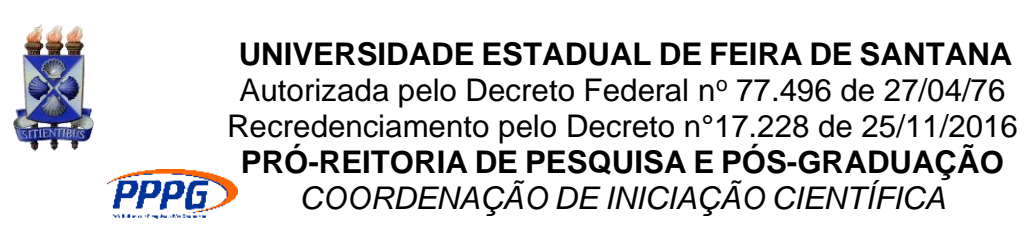

XXIII SEMINÁRIO DE INICIAÇÃO CIENTÍFICA DA UEFS SEMANA NACIONAL DE CIENTÍFICA E TECNOLÓGICA - 2020

\title{
AUTOPERCEPÇÃO DA FLUOROSE DENTAL EM DENTES ANTERIORES ENTRE ADOLESCENTES DE SERRA PRETA, UM ESTUDO CLÍNICO.
}

\footnotetext{
Willian Brito Sampaio ${ }^{1}$; Ana Rita Duarte Guimarães²; Adriana Mendonça da Silva ${ }^{3}$, Ewellyn Carvalho dos Santos ${ }^{4}$, Hervânia Santana da Costa ${ }^{5}$, Magali Teresópolis Reis Amaral ${ }^{6}$, Paulo Carvalho Tobias Duarte

1. Bolsista PROBIC/UEFS, Graduando em Odontologia, Universidade Estadual de Feira de Santana, e-mail: williansampaio1@outlook.com.br 2. Orientador, Departamento de Saúde, Universidade Estadual de Feira de Santana, e-mail: ardg199@gmail.com

3. Grupo de pesquisa em Odontopediatria, Departamento de Saúde, Universidade Estadual de Feira de Santana, e-mail: drikamendonca.am@gmail.com 4. Grupo de pesquisa em Odontopediatria, Departamento de Saúde, Universidade Estadual de Feira de Santana, e-mail: ewellyncarvalho19@gmail.com 5. Grupo de pesquisa em Odontopediatria, Departamento de Saúde, Universidade Estadual de Feira de Santana, e-mail: hervania@uol.com.br 6. Grupo de pesquisa em Odontopediatria, Departamento de Saúde, Universidade Estadual de Feira de Santana, email: mteresopolis@ hotmail.com

7. Grupo de pesquisa em Odontopediatria, Departamento de Saúde, Universidade Estadual de Feira de Santana, email: ptobias@uol.com.br
}

PALAVRAS-CHAVE: fluorose, autopercepção, qualidade de vida

\section{INTRODUÇÃO}

A fluorose dentária é descrita como uma hipomineralização difusa geralmente simétrica que ocorre no esmalte dos dentes, sendo que as suas manifestações variam da forma leve a situações consideradas graves. A forma leve evidencia-se por marcações mais finas sobre o esmalte dentário, sendo que sua aparência é geralmente quase imperceptível do esmalte normal. Já as formas moderadas e as graves são caracterizadas por hipomineralização, opacidade e porosidade acentuada do esmalte, perdendo dessa forma o seu aspecto normal de translucidez (NAGA \& PRADEEP, 2009)

É importante frisar, que nas últimas décadas com o maior acesso do flúor a população brasileira, observou-se uma diminuição da prevalência de cárie, porém também houve aumento da prevalência de fluorose dentária (MINISTÉRIO DA SAÚDE, 2012) que é caracterizado como um distúrbio da maturação do esmalte em formação, que permanece com maior porcentagem de proteínas e menos mineral. A quantidade total de fluoreto ingerida a partir de todas as fontes (água, alimentos, produtos industrializados) durante a amelogênese está diretamente relacionada com a incidência de fluorose dentária (BUZALAF, 2013). Sua manifestação clínica pode resultar em áreas de manchas esbranquiçadas ou amarronzadas e até mesmo com perda de estrutura do esmalte dental com uma forma irregular e podem ter várias tonalidades consoante o seu grau de gravidade e intensidade (BUZALAF, 2013).

Nesse sentido e levando em consideração este contexto, a aparência física do corpo, e em especial a harmonia da face, tem importante função social e psicológica na vida humana e em seus relacionamentos pessoais. Dessa forma, isso se torna de extrema relevância no período da adolescência (VIEGAS et al. 2011) por este se caracterizar por um período de grande vulnerabilidade física, psicológica e social, quando o indivíduo moldará sua identidade, fará suas escolhas e se preparará para o ingresso no mundo adulto. Nesta fase, inúmeras alterações podem afetar o estado de saúde bucal, 
apresentado potencial de comprometer a função, o bem-estar e a qualidade de vida (OLIVEIRA et al. 2013).

Diante dessas constatações, o uso de instrumentos que relacionam saúde bucal com a qualidade de vida tem aumentado nas pesquisas odontológicas com crianças e adolescentes nas últimas décadas (VIEGAS et al., 2011).

O presente relatório visa analisar os dados coletados acerca da relação entre a fluorose e a autoestima de adolescentes do município de Serra Preta-BA, localizado a $60 \mathrm{~km}$ da cidade de Feira de Santana. As coletas de dados foram realizadas nos meses de novembro e dezembro de 2019.

\section{MATERIAL E MÉTODOS OU METODOLOGIA (ou equivalente)}

Foi realizado um estudo do tipo transversal com adolescentes de 11 a 14 anos matriculados nas escolas do Município de Serra Preta - Ba, são elas: Escola Municipal Nossa Senhora do Bom Conselho, Escola Papa João Paulo I e a Escola Municipal Edith Machado Boaventura. Neste estudo, a metodologia empregada associa indicadores objetivos (dados clínicos ou epidemiológicos) que são correlacionados com indicadores subjetivos. Dentre os indicadores subjetivos está o OHRQoL (Oral Health-Related Quality of Life) que avalia o impacto da fluorose no esmalte e da cárie dentária na qualidade de vida relacionada à saúde bucal e para isso, os adolescentes foram submetidos a exame bucal visual dos dentes anteriores, com o preenchimento da ficha preconizada pela Organização Mundial de Saúde.

O diagnóstico da fluorose foi feito utilizando-se o índice de Dean, através da avaliação dos dentes anteriores, superiores e inferiores, dos adolescentes.

O impacto da fluorose foi avaliado através da aplicação OHRQoL (Oral HealthRelated Quality of Life) "um construto multidimensional que reflete, entre outras coisas, o conforto das pessoas ao comer, dormir e se envolver em interação social; sua autoestima; e sua satisfação em relação à sua saúde bucal (INSTITUTO NACIONAL DE SAÚDE, 2000).

Foi aplicado o Instrumento de Autopercepção da Aparência Dentária (IAAD), instrumento que demonstra a autoavaliação dentária que visa analisar aspectos relacionados ao bem estar do adolescente e como ele lida diante da sociedade com essa percepção da condição bucal. (SANTA-ROSA et al., 2014).

\section{RESULTADOS E/OU DISCUSSÃO (ou Análise e discussão dos resultados)}

Ao todo 56 alunos apresentaram o Termo de Consentimento Livre e Esclarecido (TCLE) assinados e puderam participar do estudo. Destes 56 escolares, 26 apresentaram algum grau de fluorose e devido a isso, somente estes puderam responder ao questionário seguinte. A partir dos dados abaixo, é possível observar que $60,7 \%$ dos escolares são do sexo feminino e cerca de 39,3\% do sexo masculino. Após tabulação, cruzamento de dados e análise de gráficos e tabela, foi possível perceber que, quando perguntado até que ponto a saúde bucal afetava a vida em geral, mais da metade dos escolares, ou seja, cerca de $65 \%$ responderam que se sentia afetado de alguma forma, seja ela "bem pouco", "moderadamente" ou "muito". Em contrapartida, cerca de $35 \%$ 
afirmaram que não perceberam nenhuma interferência da condição bucal no dia-a-dia. Ainda é válido salientar que o percentual de adolescentes que julgam a própria condição da saúde bucal como "boa" é de aproximadamente 38\% e "regular" cerca de $27 \%$, já para os que consideram "excelente" e "muito boa" é cerca de $15 \%$ cada e, $4 \%$ para os que consideram "ruim".

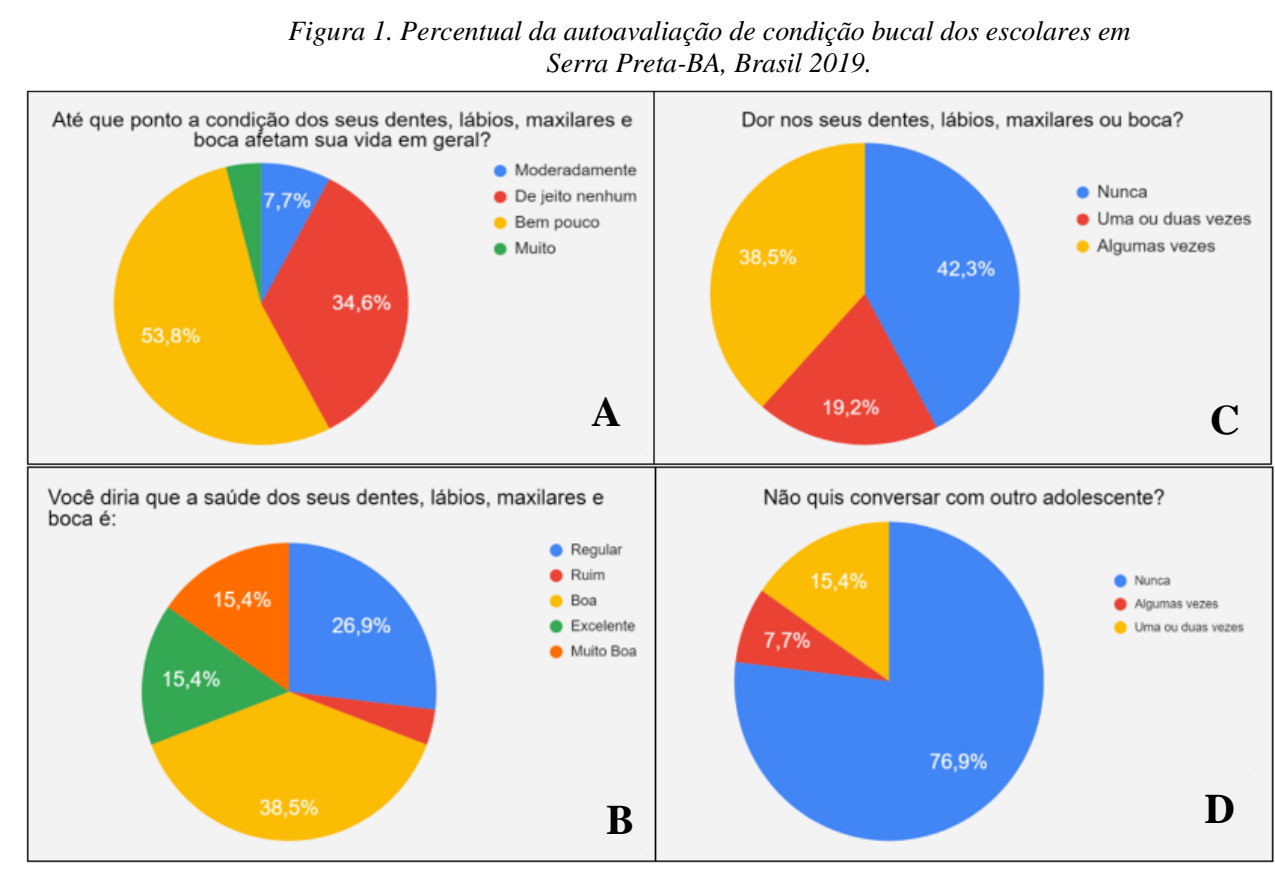

Elaboração: Willian Sampaio, 2020

Notou-se também que os indivíduos residentes na zona rural do município costumavam beber água proveniente de poço. Para aqueles que moram mais próximo do centro, notou-se um maior consumo de água mineral e água procedente da torneira, ou seja, da empresa responsável pela água de abastecimento (Embasa). Dos 16 adolescentes que residem em zona rural, 10 afirmaram que bebiam água do poço e 6 disseram que bebem água da torneira, entretanto sabe-se que na zona rural não há distribuição de água da Embasa e consequentemente, infere-se que a água também seja proveniente do poço. Em relação a escovação dentária, todos os entrevistados afirmaram a realizavam diariamente, em média de 2 a 3 vezes por dia.

Em relação ao IAAD, foi possível inferir que $46 \%$ julga a cor dos dentes normal, entretanto, quase a mesma porcentagem, ou seja, 42,3\% afirmaram que, se fosse possível, não mudaria a cor dos dentes. Este dado remete à reflexão da influência de uma sociedade que busca o "sorriso belo", impactados pelos veículos digitais, sejam eles televisivos ou redes sociais.

Ainda que grande parte dos adolescentes, cerca de $65 \%$ percebessem alguma mancha em seus dentes anteriores, uma parcela de aproximadamente $43 \%$ afirmou, ainda assim, está satisfeita com a atual situação. Isso pode ser justificado pela dificuldade de acesso aos serviços de saúde bucal, aliado à falta de condições financeiras para sair de seu município em busca do atendimento necessário. 


\section{CONSIDERAÇÕES FINAIS (ou Conclusão)}

$\mathrm{Na}$ amostra pesquisada, verificou-se relação entre autoestima dos adolescentes e fluorose dentária. Dentre os fatores que interferiram na autoestima dos adolescentes, além da fluorose dentária, também tiveram importância a condição bucal geral, ou seja, dores e manchas nos dentes, lábios ou alguma alteração na anatomia dentária.

A procedência da água ingerida, quantidade diária de escovações, bem como as condições socioeconômicas do indivíduo e o impacto das suas condições bucais nas suas atividades cotidianas e escolares deram melhor entendimento do panorama sobre a autopercepção da fluorose desta população.

\section{REFERÊNCIAS}

BRASIL. MINISTÉRIO DA SAÚDE. SECRETARIA DE ATENÇÃO À SAÚDE. SECRETARIA DE VIGILÂNCIA EM SAÚDE. SB Brasil 2010: Pesquisa nacional de saúde bucal: resultados principais. 2012.

BUZALAF, Maria Afonso Rabelo. Fluoretos e Saúde Bucal, $2^{a}$ edição. Santos, 2013.

CUNNINGHAM, S. J.; HUNT, N. P. Quality of life and its importance in orthodontics. Community Dent. Oral Epidemiol., Adelaide, v. 28, n. 8, p. 152-158, 2001.

DE OLIVEIRA, Branca Heloisa; NADANOVSKY, Paulo. Psychometric properties of the Brazilian version of the Oral Health Impact Profile-short form. Community dentistry and oral epidemiology, v. 33, n. 4, p. 307-314, 2005

GONÇALVES, Juliana Rocha et al. Impactos da saúde bucal sobre a qualidade de vida entre homens e mulheres. RGO-Revista Gaúcha de Odontologia, v. 52, n. 4, $2004 .$. RGO Vol. 52, $\mathrm{N}^{\circ}$ 4, 2004

LOCKER, David; SLADE, Gary. Association between clinical and subjective indicators of oral health status in an older adult population. Gerodontology, v. 11, n. 2, p. 108-114, 1994.

NAGA, B. \& PRADEEP, V. R. N. Fluorosis in the early permanent dentition: evaluating gene-environment interactions. 2009. 154p. Dissertação (Mestrado Saúde Pública Bucal) - University of Iowa, Iowa, 2009

OLIVEIRA, Diego Canavese et al. Reported Impact of Oral Alterations on the Quality of Life of Adolescents: A Systematic Review. Pesquisa Brasileira em Odontopediatria e Clinica Integrada, v. 13, n. 1, p. 123-129, 2013.

SANTA-ROSA, Thalita Thyrza De Almeida et al. Impact of aesthetic restorative treatment on anterior teeth with fluorosis among residents of an endemic area in Brazil: intervention study. BMC oral health, v. 14, n. 1, p. 52, 2014.

SLADE, Gary D. Derivation and validation of a short-form oral health impact profile. Community dentistry and oral epidemiology, v. 25, n. 4, p. 284-290, 1997.

VIEGAS, Cláudia Marina et al. Fluorose dentária: abordagens terapêuticas para recuperação estética. RGO. Revista Gaúcha de Odontologia (Online), v. 59, n. 3, p. 497$501,2011$.

WHOQOL GROUP et al. The World Health Organization quality of life assessment (WHOQOL): position paper from the World Health Organization. Social science \& medicine, v. 41, n. 10, p. 1403-1409, 1995. 